\title{
DA SUSPEITA AO DIAGNÓSTICO DE CÂNCER INFANTOJUVENIL: A EXPERIÊNCIA DE FAMILIARES EM SERVIÇOS DE SAÚDE
}

FROM SUSPICION TO DIAGNOSIS OF CHILDHOOD AND ADOLESCENT CANCER: THE EXPERIENCE OF FAMILY MEMBERS IN HEALTH SERVICES

BEATRIZ LIMA FIGUEIRÊDO ${ }^{1}$

SIBELLE MARIA MARTINS DE BARROS ${ }^{1}$

MARIA ANGÉLICA CARVALHO ANDRADE ${ }^{2}$

1 Universidade Estadual da Paraíba, Campina Grande/PB, Brasil

${ }^{2}$ Universidade Federal do Espírito Santo (UFES), Vitória, Espírito Santo, Brasil
RESUMO: Neste trabalho buscou-se compreender a experiência de familiares de crianças e adolescentes com câncer, nos serviços de saúde, desde os primeiros sinais e sintomas da doença até a comunicação do diagnóstico. Trata-se de um estudo qualitativo realizado com 20 cuidadores familiares de crianças e adolescentes que estavam em tratamento oncológico em um hospital público da Paraíba. Recorreu-se à entrevista semiestruturada para apreensão dos dados e à análise de conteúdo, do tipo temático, para a organização e análise dos resultados. 0 processo de análise permitiu a construção de três categorias temáticas: Em busca de um diagnóstico; Diagnóstico; e Mudanças no sistema familiar. Recorrer a vários serviços de saúde, esperar pelo diagnóstico e, por vezes, receber diagnósticos errados causaram sofrimento na família, que geralmente se sentia negligenciada e impotente. Apesar de grande parte dos cuidadores avaliar a comunicação do diagnóstico como adequada, as reações dos cuidadores expressaram o choque surgido pela notícia. Nesse cenário, identificou-se uma maior união na maioria das famílias e mudanças de rotina e papéis, no sentido de adaptação à adversidade inesperada. Ressalta-se a importância de repensar as práticas de cuidado na rede de assistência oncológica, assegurando uma postura de acolhimento e vínculo, a partir da ótica da integralidade.

Palavras-chave: Câncer infantojuvenil; Família; Assistência à saúde.

ABSTRACT: This work sought to understand the experience of family members of children and adolescents with cancer, in health services, from the first signs and symptoms of the disease to the communication of the diagnosis. It is a qualitative study conducted with 20 family caregivers of children and adolescents who were undergoing cancer treatment at a public hospital in Paraíba. Semi-structured interviews were used to apprehend the data, and thematic content analysis was used for results organization and analysis. The analysis process allowed the construction of three thematic categories: In search of a diagnosis; Diagnosis; and Changes in the family system. Resorting to various health services, waiting for the diagnosis and sometimes receiving wrong diagnoses caused suffering in the family, which generally felt neglected and powerless. Although most caregivers evaluate the communication of the diagnosis as adequate, the caregivers' reactions expressed the shock that emerged from the news. In this scenario, greater unity was identified in most families as well as changes in routine and roles, in the sense of adapting to unexpected adversity. The importance of rethinking care practices in the oncology care network is emphasized, ensuring a welcoming and bonding posture, from the perspective of integrality.

Keywords: Childhood cancer; Family; Health care.

RESUMEN: En este trabajo se buscó comprender la experiencia de familiares de niños y adolescentes con cáncer, en los servicios de salud, desde los primeros signos y síntomas de la enfermedad hasta la comunicación del diagnóstico. Se trata de un estudio cualitativo realizado con 20 cuidadores familiares de niños y adolescentes que estaban en tratamiento oncológico en un hospital público de Paraíba. Se recurrió a la entrevista semi estructurada para la aprehensión de los datos y el análisis de contenido, de tipo temático, para la organización y análisis de los resultados. El proceso de análisis permitió la construcción de tres categorías temáticas: En búsqueda de un diagnóstico; Diagnóstico; y Cambios en el sistema familiar. Recorrer a varios servicios de salud, esperar por el diagnóstico y, a veces, recibir diagnósticos equivocados causaron sufrimientos en la familia, que generalmente se sentía abandonada e impotente. A pesar de que gran parte de los cuidadores evalúan como adecuada la comunicación del diagnóstico, las reacciones de los cuidadores dieron muestra del shock producido por la noticia. En ese scenario, se identificó una mayor unión en la mayoría de las familias y cambios de rutina y roles, en el sentido de adaptación a la adversidad inesperada. Se resalta la importancia de repensar las prácticas de cuidado en la red oncológica, asegurando una postura de acogimiento y vínculo, a partir de la óptica de la integralidad.

Palabras clave: Cáncer infanto-juvenil; Familia; Asistencia a la salud.
Recebido em 13/04/2020 Aprovado em 06/07/2020 


\section{INTRODUÇÃO}

O conhecimento científico acerca do câncer infantojuvenil cresceu significativamente nas últimas décadas. A doença, que antes era pouco percebida e estudada, tornou-se a primeira causa de morte por doença entre crianças e adolescentes de um a dezenove anos no Brasil (INCA, 2020). Contudo, atualmente existem chances de cura para até $80 \%$ dos casos, se diagnosticados precocemente e se submetidos a procedimentos especializados adequados (Amador, Reichert, Lima, \& Collet, 2013).

Ainda que se reconheça a importância de um rápido diagnóstico para um melhor prognóstico do câncer infantojuvenil, concluí-lo precocemente constitui um desafio. Aspectos como a imprecisão dos sinais e sintomas do câncer, que podem se confundir com outras patologias comuns nessa faixa etária, e a qualidade do atendimento recebido pelos profissionais de saúde, podem dificultar a conclusão do diagnóstico (Friestino, 2015; Reis, Dias, \& Mazzaia, 2009). Tal dificuldade pode acarretar, entre outras coisas, o prolongamento do itinerário terapêutico, que se inicia quando a família percebe que os sinais e sintomas apresentados pelas crianças ou adolescentes merecem atenção e cuidados em saúde (Rezende, Schall, \& Modena, 2009).

A experiência com o câncer pode tornar-se mais difícil considerando o caminho a ser percorrido pela criança ou adolescente e sua família em serviços de saúde, além do fato de ter que lidar com a representação simbólica de morte, incurabilidade, perdas e intenso sofrimento que envolve o adoecer de câncer (Almico \& Faro, 2014; Borges, Lima, \& Dupas, 2016; Del Bianco Faria \& Cardoso, 2010; Kohlsdorf \& Costa, 2012; Nehmy, Brito, Mota, \& Oliveira, 2011).

As reações às enfermidades e às estratégias de enfrentamento dependem não apenas de processos individuais, mas de relações e contextos que permitam às famílias construírem recursos para lidarem com um evento inesperado. Como discute Rolland (2016), o enfrentamento de uma doença envolve tarefas para a família que implicam a participação de outros atores sociais, como os profissionais de saúde. $\mathrm{Na}$ fase inicial, por exemplo, espera-se que a família aprenda a lidar com os sintomas, adapte-se aos contextos dos serviços de saúde, estabeleça boas relações com os profissionais de saúde e construa um significado para a doença. Acreditase que, nesse cenário, os profissionais de saúde possuam grande influência no sentimento de competência e nas estratégias que a família utiliza para lidar com esse desafio desenvolvimental, evitando, sobretudo, culpabilizações diretas ou implícitas que minam tais recursos.

Nessa perspectiva, tendo em vista que a orientação e o preparo dos familiares contribuem para a diminuição do impacto do diagnóstico, além de ajudar na adaptação à nova situação (Alves \& Eulálio, 2011), neste estudo propôs-se compreender a experiência de familiares de crianças e adolescentes com câncer nos serviços de saúde desde os primeiros sinais e sintomas da doença até a comunicação do diagnóstico.

Espera-se que estudos neste escopo possam promover reflexões que contribuam para a melhoria da assistência à saúde voltada ao paciente oncológico e sua família, buscando potencializar o bem-estar, a qualidade de vida e o desenvolvimento de todos os envolvidos, a partir da ótica da complexidade e da integralidade em saúde. A integralidade, princípio destacado na proposta do Sistema Único de Saúde (SUS), implica a consideração de diferentes aspectos que fazem parte da vida dos sujeitos, como aspectos biológicos, psicológicos, sociais, dentre outros, que engendram diferentes contextos e histórias de vida. O projeto político do SUS, nesse sentido, propõe uma mudança paradigmática, um reordenamento epistemológico que 
permite ressignificar modelos, práticas e o próprio conceito de saúde (Boing \& Crepaldi, 2014). As pesquisas científicas, por sua vez, podem contribuir para a consolidação dos princípios e diretrizes do SUS, apontando demandas que são identificadas nas investigações realizadas em diversas regiões do Brasil.

\section{METODOLOGIA}

Trata-se de um estudo descritivo, exploratório, com abordagem qualitativa, uma vez que esta possibilita maior aproximação com o cotidiano e as experiências vividas pelos próprios sujeitos, permitindo ao pesquisador interpretar os fenômenos em termos de significados atribuídos pelas pessoas investigadas (Denzin \& Lincoln, 2006; Minayo, 1993). Participaram 20 cuidadores familiares de crianças e adolescentes que estavam em tratamento oncológico em um hospital público da Paraíba. Dentre esses, 19 eram mães e apenas um cuidador era pai, que compartilhava o cuidado da criança com a mãe. A escolha se deu por conveniência, de acordo com a disponibilidade dos familiares nos dias de coleta, sendo utilizados os seguintes critérios de inclusão: ser cuidador familiar principal; estar acompanhando crianças ou adolescentes que tinham diagnóstico de câncer e que estavam hospitalizados no setor de oncologia pediátrica do hospital; aceitar participar da pesquisa e consentir com as etapas e procedimentos da mesma a serem esclarecidos antes da realização da coleta.

Antes do início da coleta, o projeto de pesquisa foi apresentado aos profissionais de saúde da Oncologia Pediátrica para que os mesmos pudessem conhecer seus objetivos e compreender sua importância acadêmica e social. Em seguida, os cuidadores que acompanham crianças e adolescentes na enfermaria do referido setor foram convidados individualmente a participarem da pesquisa. Nessa ocasião, foram explicados os objetivos da pesquisa, os direitos dos participantes por meio do Termo de Consentimento Livre e Esclarecido (TCLE), de acordo com a Resolução n. 466/12 do Conselho Nacional de Saúde, e investigado o interesse em participar do estudo. De 21 cuidadores abordados, quase todos concordaram em participar da pesquisa. Apenas uma cuidadora desistiu da participação após o início da entrevista, uma vez que, segundo ela, relembrar a trajetória percorrida pela família era motivo de muito sofrimento. Diante de situações como essa, era oferecido aos cuidadores um espaço de escuta qualificada, nas dependências do próprio hospital, de modo a permitir a expressão de seus sentimentos e emoções, oferecer apoio emocional e contribuir para o processo de ressignificação das vivências relacionadas ao adoecimento de seus filhos.

Como previsto, foram coletadas as assinaturas dos TCLE e do Termo de autorização para gravação de voz de todos os cuidadores que aceitaram participar da pesquisa e, logo em seguida, foi realizada a coleta de dados na enfermaria da oncologia pediátrica.

Foram realizadas entrevistas individuais semiestruturadas, as quais foram submetidas à análise de conteúdo temática (Bardin, 2009). Após a organização e leitura flutuante do material, as entrevistas foram demarcadas em unidades de registro, a partir dos temas evocados do texto, possibilitando o processo de codificação. Dessa forma, buscou-se identificar os sentidos das unidades de registro, por meio da construção de códigos semânticos. Por fim, por meio do agrupamento de códigos com semelhanças semânticas, foram construídas subcategorias e categorias temáticas.

A fim de garantir o anonimato dos participantes e a confidencialidade das respostas, utilizou-se um sistema de identificação no qual seus respectivos nomes

Nova Perspectiva Sistêmica, v. 29, n. 67, p. 98-113, agosto 2020. 
foram substituídos pela letra C (referente a "cuidador"), seguida de um algarismo numérico que representa a ordem de aplicação dos instrumentos.

Este estudo foi aprovado pelo Comitê de Ética de Pesquisa (CEP) da Universidade Estadual da Paraíba, segundo parecer n. 1.998.525 tendo como base as normatizações preconizadas na Resolução n. 466, de 12 de dezembro de 2012, do Conselho Nacional de Saúde (CNS).

\section{RESULTADOS E DISCUSSÃO}

A partir da análise de conteúdo temática, foi possível construir três categorias relacionadas à experiência das famílias no processo inicial do tratamento médico da criança ou do adolescente: Em busca de um diagnóstico; Diagnóstico e Mudanças no sistema familiar. Optou-se por apresentar alguns recortes de entrevistas, no sentido de ilustrar o sentido das subcategorias que compõem as categorias temáticas.

\section{Em busca de um diagnóstico}

Essa categoria englobou as seguintes subcategorias: o processo de investigação clínica; os serviços percorridos e a assistência recebida durante o período de busca de respostas aos sintomas apresentados pelas crianças e adolescentes.

O itinerário das famílias iniciou-se no momento em que se identificou o aparecimento de variados sinais e sintomas, dando-se início ao processo de investigação clínica. A febre era o sintoma mais recorrente, presente em quase todos os casos, de forma isolada ou acompanhada por outros sinais como, por exemplo, gripe e manchas na pele: "Apareceram manchas nas pernas e febre de $40^{\circ "}$ (C3), "Passou uma semana tendo febre" (C5), "Ela já começou a ter febre e a tossir" (C7).

Em algumas situações, os sintomas apresentados pareciam indicar outro problema de saúde:

Ele começou a ter umas manchas vermelhas na pele, aí quando ia desmanchando ia ficando roxo. Foi só o que ele teve. Aí eu levei pro posto, pensavam que era machucado ou alguma coisa assim. Aí depois ele começou a ter febre, aí eu levei de novo, passaram remédio e mandaram pra casa. Sei que a febre ia e voltava, ia e voltava. Só quando foi na quarta vez que a gente foi, foi que pediram um exame de sangue. (C15)

Houve relatos, ainda, de famílias que descobriram o câncer quando investigavam outras questões de saúde que não se relacionavam com a sintomatologia dessa patologia:

Nesse tempo nasceu um dente no céu da boca dele, [...] aí o dentista pediu exame de sangue e raio $\mathrm{x}$ da boca dele. Aí eu trouxe ele pra um laboratório particular aqui e fiz um exame, aí quando saiu o resultado a médica me deu um bilhetinho e os exames que ele tinha pedido. Aí ela disse pra eu procurar o médico do posto de saúde, só que o médico não tava, aí eu mostrei à enfermeira. Assim que ela viu, disse que ia me encaminhar pra cá pra Campina. (C9). 
Os serviços de saúde percorridos pelas famílias variaram em relação à porta de entrada, à quantidade de idas e vindas e de encaminhamentos em busca de um diagnóstico adequado. Enquanto alguns participantes buscaram os serviços de atenção primária como porta de entrada no Sistema Único de Saúde (SUS), outros recorreram aos níveis secundários e terciários. Houve relatos, ainda, de cuidadores que iniciaram a investigação no serviço privado de saúde.

Dos vinte entrevistados, dez cuidadores procuraram inicialmente a Unidade Básica de Saúde, enquanto dois recorreram aos serviços de pronto atendimento, seis aos hospitais públicos e dois aos consultórios da rede privada de saúde: "Adriano não tava comendo direito de noite, só queria ficar deitado, tava fraco. Sei que ele ficou bem uma semana assim, aí depois começou a febre. Eu levei ele no posto de saúde da minha cidade" (C12); "Passou uma semana tendo febre, aí quando foi depois de uma semana eu trouxe ela pra o hospital" (C5).

No que tange à assistência à saúde, onze participantes relataram que houve pouca investigação por parte da equipe médica. Dois cuidadores, inclusive, pediram a profissionais da rede pública e privada que fossem realizados exames, no intuito de aprofundar a investigação do problema. As solicitações não foram acatadas pelos médicos, como demonstra o relato abaixo:

Em janeiro ele teve uma gripe, aílevamos pra pediatra e ela passou medicamento, aí ficou bom. Em fevereiro essa gripe voltou bem mais forte, aí levamos ele pra pediatra de novo, e pedimos até pra ela passar um hemograma, porque a gente tava achando ele meio pálido, aí ela não passou, disse que ia seguir o protocolo médico. Ela passou antibiótico, aí ele tomou por uma semana e não resolveu. Aí a gente voltou de novo, ela passou outro antibiótico e não passou o hemograma, e foi porque a gente pediu de novo. (C16)

Nos casos investigados na rede pública ainda existia outra problemática: a demora para o agendamento dos exames e, consequentemente, acesso aos resultados, prolongando, assim, a angústia da incerteza em relação ao adoecimento. Estes fatos fizeram com que alguns familiares que haviam iniciado a investigação na rede pública recorressem, por conta própria, à rede privada de saúde, na tentativa de conseguir um diagnóstico e iniciar o tratamento mais rápido.

Outra questão identificada nos relatos de forma bastante frequente refere-se à ocorrência de diagnósticos incorretos antes de se chegar, de fato, ao diagnóstico de câncer. Esses diferentes diagnósticos antes da confirmação do câncer, que também foram identificados em outros estudos (Fermo, Lourençatto, Medeiros, Anders, \& Souza, 2014; Lima, Silva, Góes, Ribeiro, \& Alves, 2018), podem contribuir para a piora do quadro clínico da criança ou adolescente, como exemplificado na fala deste cuidador:

As suspeitas era ou leucemia ou infecção viral. [...] Aí deram alta a ele como infecção viral. A gente foi pra casa e ele ficou tomando antibiótico. Com quinze dias começou a aparecer outros sintomas. [...] Aí a gente trouxe ele de volta pra cá e a suspeita foi muito maior da leucemia. (C16)

O processo de investigação de um quadro clínico é um momento geralmente difícil para as famílias, principalmente àquelas que suspeitam da possibilidade de um câncer, patologia carregada socialmente de estigmas e preconceitos. Vivenciar a espera e a falta de informações acerca do adoecimento do filho, vendo os sintomas se intensificarem, pode trazer estresse e ansiedade às famílias que, embora possam 
temer o diagnóstico, o buscam incessantemente, a fim de poder iniciar uma terapêutica que cesse ou amenize aqueles sintomas (Borges, 2013).

Interessante ressaltar que dez cuidadores buscaram os primeiros cuidados na atenção básica, representada pelas Unidades Básicas de Saúde. Entretanto, dois cuidadores buscaram atendimento em consultórios médicos particulares e oito buscaram serviços hospitalares ou de pronto atendimento, seja pela angústia em resolver o problema da forma mais rápida possível ou por falta de conhecimento do funcionamento da rede de saúde. Esse dado reflete as dificuldades estruturais do SUS, como a demora para ter acesso aos exames, mas também denuncia a falta de uma postura acolhedora que permita uma escuta empática, por parte dos profissionais de saúde, na assistência prestada, seja no SUS ou na rede particular. A ausência do acolhimento, por sua vez, acarretou vários encaminhamentos e procedimentos inadequados para se chegar ao diagnóstico, submetendo a família a uma "peregrinação exaustiva", refletindo a falta de resolutividade da assistência. As diversas idas e vindas aos serviços de saúde parecem ser uma característica comum no percurso percorrido pelas famílias até o câncer ser identificado (Lima, Silva, Góes, Ribeiro, \& Alves, 2018; Rezende, 2015), aumentando-o ainda mais e adiando a conclusão do diagnóstico (Vidotto, Ferrari, Tacla, \& Facio, 2017).

Os erros de diagnóstico podem ser justificados pela similaridade da sintomatologia com outras patologias mais frequentes na infância e adolescência, ou ainda pela pequena quantidade de casos de neoplasias presenciados pelos profissionais de saúde nesta população, se comparado às outras doenças com sintomatologia similar (Sá, Silva, \& Góes, 2019). Embora dificilmente suspeite-se da possibilidade do câncer nos primeiros dias, após duas semanas de sintomas recorrentes, e que não respondam ao tratamento proposto, o INCA (2020) recomenda que a investigação de câncer seja iniciada, dada a necessidade do diagnóstico precoce. Há de se levar em conta que esse prazo pode ser considerado longo pelos familiares que já percebem sintomas, provavelmente, há mais tempo. Contudo, não se pode negligenciar o fato de que alguns profissionais de saúde não seguem essa recomendação, conforme foi demonstrado no relato de alguns cuidadores que afirmaram, com o passar dos dias, ser necessário recorrer várias vezes ao serviço de saúde, na tentativa de obter alguma informação concreta e pertinente sobre o adoecimento de seu filho.

A inexistência ou fragilidade do vínculo entre profissionais de saúde e usuários provavelmente contribui para a dificuldade de se chegar a um diagnóstico. Alguns participantes relataram que, apesar de discorrerem sobre a recorrência dos sintomas, parecia não existir uma escuta atenciosa aos seus relatos no momento da consulta. Tendo em vista que o vínculo, enquanto ferramenta e tecnologia fundamental da atenção básica, permite ampliar o conhecimento sobre as vivências das famílias, possibilitando um cuidado centrado em suas demandas e necessidades (Seixas et al., 2019), deve ser reconhecido em sua potência transformadora das relações e da resolutividade dos problemas de saúde.

A queixa dos cuidadores em ter que insistir para que as investigações sejam aprofundadas por meio de solicitação de exames e atenção às queixas da criança ou adolescente é algo constatado em estudos anteriores (Cavicchioli, Menossi, \& Lima, 2007; Fermo, Lourençatto, Medeiros, Anders, \& Souza, 2014) e também denuncia a fragilidade dos vínculos construídos com a família na rede de atenção à saúde e traz à luz reflexões acerca da hierarquia socialmente existente entre o médico - aquele que detém o saber, e o doente/ a família - aquele que não o detém (Piccardi, 2012). Está relacionado, portanto, à dificuldade de prestar uma assistência humanizada, que, de acordo com Bidin, Souza, e Machineski (2013), baseia-se no diálogo, na compreensão, no saber ouvir e compreender as angústias e o sofrimento das famílias.

Nova Perspectiva Sistêmica, v. 29, n. 67, p. 98-113, agosto 2020. 
A categoria "diagnóstico" envolve o momento da comunicação diagnóstica aos cuidadores e suas respectivas reações.

O diagnóstico, em quase todos os casos, foi comunicado à mãe que estava, na maioria das vezes, sozinha. Duas comunicações foram direcionadas à tia de uma criança e ao companheiro de uma adolescente. A presença constante das mães enquanto cuidadoras confirma que, mesmo diante de todas as transformações ocorridas no que diz respeito ao papel da mulher na sociedade, a ideia da figura feminina como aquela que detém a responsabilidade sobre o cuidado ainda é muito forte (Salci \& Marcon, 2008). Além disso, pode ser importante, para ela, sentir que está desempenhando o papel de boa mãe ao atender, sempre que possível, às demandas do filho (Nunes, Pedrosa, Barbosa, Monteiro, \& Ferraz, 2017).

Para a maioria dos cuidadores a forma de comunicação do diagnóstico representou acolhimento e trouxe esclarecimentos acerca da doença e do tratamento: "Aí a doutora explicou bem direitinho que a gente ia vir pra o hospital, como é que ia ser o tratamento dele, que era uma doença agressiva. Eles explicaram tudo" (C6). "Ela explicou que era leucemia e que o tratamento era assim. Aí eu perguntei a ela: 'doutora, meu filho vai morrer?' E ela disse que não sabia, mas que tudo o que pudesse fazer por ele iria fazer" (C9).

Os cuidadores demonstraram sentir-se satisfeitos quando a revelação do diagnóstico foi feita de forma franca e aberta, respeitando suas necessidades quanto ao tempo para digerir as informações: "A gente sempre falou que queria que eles fossem sempre claros com a gente. Então da forma que foi passado não sentimos tanto, porque eles sempre iam preparando, entendeu?" (C16).

A satisfação relatada por esses cuidadores deve-se ao fato de as informações terem sido repassadas com uma linguagem clara e acessível, aspectos fundamentais para evitar falsos entendimentos no cuidador, aspectos que podem intensificar o estresse e ansiedade (Alcântara, Shioga, Lima, Lage, \& Maia, 2013). Destaca-se, ainda, a importância da dimensão afetiva na comunicação do diagnóstico representada pela postura de acolhimento dos profissionais.

Por outro lado, para três cuidadores, as comunicações ocorreram de forma inadequada, inclusive com culpabilização da família, como exemplificado na seguinte fala: "Foi muito difícil! Ela olhou pra mim e fez 'Mãe, como você deixou a sua filha chegar nessa situação? Como foi que você deixou a sua filha se acabar aos poucos desse jeito?'” (C10). Comunicações como essas denotam a ocorrência de violência institucional e exercício de poder decorrentes de relações assimétricas, ainda valorizadas por alguns profissionais. Elas podem ser prejudiciais na relação de confiança entre equipe, paciente e família, interferindo, entre outras coisas, na adesão ao tratamento (Ferreira, Duarte, Machado, Brandão, Baiense, Mello, \& Vitarelli, 2018). Alerta-se para o fato de que o próprio processo de adaptação e significação do diagnóstico de câncer infantil pode envolver o sentimento de culpa dos progenitores, fazendo emergir comportamentos compensatórios, como uma maior atenção ao filho por meio da abdicação das atividades cotidianas parentais (Frizzo et al., 2015). Ademais, culpabilizar os pais prejudica o enfrentamento da situação, podendo contribuir para o surgimento da ideia de punição, aumento do sentimento de incompetência e desesperança.

No que se refere às principais reações emocionais relacionadas ao impacto do diagnóstico, foi possível identificar desespero, tristeza e choque: "Eu fiquei muito triste mesmo. Eu fiquei desesperada, fiquei com ar de louca dentro do hospital, chorando!" (C17); "Nessa hora, por mais que você tenha fé, seu mundo desaba. É um 
impacto muito grande. Nessa hora não existe supermãe, não existe supersserva, não existe nada. Seu mundo cai, seu chão desaparece, sabe? É uma dor que você não sabe o que fazer... é um desespero" (C6).

As reações ao diagnóstico indicam a proximidade semântica do câncer com a morte, como verbalizado por alguns familiares: "Quando descobri, eu senti que ali pra mim era ofim e que eu tava perdendo meu filho" (C4). Sentimentos como a tristeza e o medo da morte podem estar presentes não só no momento da comunicação do diagnóstico, mas também no cotidiano dos cuidadores, podendo levar a pensamentos negativos, facilitando desestruturações pessoais e sintomas de estresse. Casos como esses reforçam a necessidade de a equipe de saúde atuar com o propósito de garantir o suporte necessário para os cuidadores lidarem com o adoecimento (Del Bianco Faria \& Cardoso, 2010; Mazza, Lima, Carvalho, Weissheimer, \& Soares, 2017).

Por fim, embora em número bem menos frequente, chama atenção o relato de alguns cuidadores que, ao descreverem como se sentiram em relação ao diagnóstico, citaram sentimentos como força e calma: "Eu me senti forte, porque a gente sempre tem que tá forte pra dar força pra ele" (C16); "Eu me desesperei, mas na mesma hora eu me acalmei. A gente tem que aceitar, né? Tem que conviver com isso e ficar calma pra poder cuidar dela" (C14). Falas como essas parecem demonstrar uma tentativa de autocontrole frente ao diagnóstico, o que não descarta outras reações à má notícia. A calma e aceitação, contudo, são mais comuns depois de passado o impacto do diagnóstico, quando os cuidadores geralmente refletem e começam a compreender que precisam buscar forças para reagir na tentativa de transmitir força à criança ou adolescente doente (Carvalho, Depianti, Silva, Aguiar, \& Monteiro, 2014).

A forma de comunicação do diagnóstico é crucial para o estabelecimento de uma relação de confiança entre a equipe de saúde, o paciente e a família, facilitando a conscientização sobre a gravidade da situação e proporcionando melhor adesão ao tratamento, de modo que o cuidado possa ser efetivado (Beltrão, Vasconcelos, Pontes, \& Albuquerque, 2007; Theobald, Santos, Andrade, \& De-Carli, 2016). A existência de uma comunicação respeitosa e dialógica entre equipe e familiares permite trocas de saberes, construção colaborativa de possibilidades de cuidado, de modo que a família possa se sentir acolhida no momento do diagnóstico. Trata-se, pois, de um elemento fundamental para que o profissional de saúde possa instituir um vínculo com a família, possibilitando uma assistência humanizada com base em tecnologias leves de cuidado (Merhy, 2007; Theobald et al., 2016).

Uma comunicação inadequada, por sua vez, além de dificultar o enfrentamento da doença (Ongaro \& Zucolotto, 2016), por minar o sentimento de competência da família, reflete o despreparo e a falta de ética profissional e, além de não satisfazer às necessidades do usuário, promove um sofrimento adicional e desnecessário ao mesmo, comprometendo o cuidado (Aguiar, D'Oliveira, \& Schraiber, 2013; Theobald et al., 2016). A falta de respeito e a violência verbal perpetradas por alguns profissionais de saúde durante a comunicação do diagnóstico apontam entraves da proposta de humanização em saúde. Todavia, ações desrespeitosas ainda são reproduzidas com naturalidade no contexto do cuidado, sendo corriqueiramente praticadas por alguns profissionais de saúde, por não reconhecerem suas atitudes como violadoras dos direitos dos usuários (Fornari, Madureira, Labronici, \& Mantovani, 2014).

É preciso considerar que o câncer possui sentidos relacionados à dor, sofrimento e morte, fator que pode intensificar a angústia da família, especialmente se ela não receber as informações suficientes que lhe possibilitem o conhecimento necessário para lidar com o adoecimento de seus filhos (Almico \& Faro, 2014). Além disso, na maioria das vezes, o cuidador não conhece a fundo as características da doença e

Nova Perspectiva Sistêmica, v. 29, n. 67, p. 98-113, agosto 2020. 
do seu tratamento, especialmente se não estiver vivenciado anteriormente um câncer no contexto familiar. Nesta perspectiva, Sales, Santos, Santos, e Marcon (2012) explicam que, dependendo da forma como é feita, a transmissão da informação pode acabar sendo prejudicada pelo conhecimento restrito da família em relação à fisiopatologia da doença. Assim, a equipe de saúde deve empregar uma linguagem coerente com a realidade de cada família, proporcionando os esclarecimentos e apoio necessários para um cuidado humanizado, minimizando os possíveis danos físicos e psicológicos que podem resultar do diagnóstico e dos momentos seguintes a ele. Dessa maneira, e de acordo com a afirmativa de Martins, Silva, e Pires (2011), o cuidador familiar poderá sentir-se mais seguro para enfrentar os novos desafios advindos da experiência, como a consequente necessidade de alterações na rotina, considerando as visitas constantes ao médico, o tratamento exigido pela doença, as hospitalizações e os novos cuidados que o paciente demanda.

\section{Mudanças no sistema familiar}

A categoria "Mudanças no sistema familiar" refere-se às transformações familiares em decorrência do diagnóstico, como aproximação ou afastamento de familiares, mudanças na rotina e reorganização de papéis.

Entre as principais mudanças ocorridas nas famílias, após o adoecimento da criança ou do adolescente, destacou-se a aproximação dos membros, no intuito de oferecer o suporte necessário ao paciente: "Ah, todo mundo se aproximou. A nossa família tá ainda mais unida agora. Todo mundo mesmo" (C6).

Um número bem menor de cuidadores relatou o afastamento de seus membros após o diagnóstico:

Eles disseram que não iam mais na minha casa. Até uma irmã, que tava morando mais eu, saiu de dentro da minha casa. Nem os vizinhos chegam na minha porta. Quando chega uma criança na minha porta, as mães puxam pra não pegar. Tem muita gente ignorante aí, gente que não entende as coisas, que pensa que isso pega, mas não pega. (C9)

Uma maior união do sistema familiar demonstra que houve mobilização de membros da família, de modo a ofertar apoio ao membro doente e ao seu cuidador principal, fato que possibilita um melhor enfrentamento das mudanças decorrentes do adoecer de câncer (Melo et al., 2012). A fragilidade decorrente da doença, portanto, pode ser capaz de trazer à tona sentimentos de carinho, amor e cuidado que antes poderiam ter sido esquecidos ou demonstrados com menor frequência (Ferreira, Dupas, Costa, \& Sanchez, 2010), atuando como uma rede de apoio voltada ao cuidador.

O afastamento de alguns membros da família pode ser uma tentativa de afastarse emocionalmente do membro que está doente (Salvagni, 2014). No entanto, nesse estudo, o afastamento de familiares relaciona-se mais ao estigma e à falta de conhecimento sobre a doença. O preconceito e a curiosidade de terceiros em relação à doença, fruto de um desconhecimento de suas causas, acabam afastando pessoas significativas para os familiares, acentuando sentimentos de isolamento vivenciados por eles e seus filhos, aumentando o sofrimento destes (Fagundes, Silva, Silva, \& Barbosa, 2015).

Os cuidadores também relataram mudanças ensejadas pela rotina terapêutica, tais como a necessidade de visitas frequentes e, muitas vezes, permanentes ao 
ambiente hospitalar e o consequente afastamento domiciliar: "Muda né? Porque a gente vive dentro do hospital, a gente não vive em casa mais..." (C5). Essas mudanças podem provocar uma ruptura na unidade familiar, acarretando um desequilíbrio no funcionamento da família, tornando-a mais vulnerável (Quirino, 2011). Todavia, buscando driblar esse desequilíbrio, foi possível perceber que os demais membros da família também precisaram se reorganizar, fomentando a mudança nos papéis de todos os membros para adaptar-se à nova situação: "meus meninos agora têm que cuidar dos outros, as duas moças cuidam da casa, dos pequenos, de tudo. E tem meu menino que tá trabalhando pra umas pessoas da igreja agora" (C12).

Esta delegação de tarefas parece ser uma das primeiras atitudes tomadas pelo cuidador ao ter que se ausentar de casa por alguns dias ou meses, na tentativa de manter o funcionamento familiar. Em um estudo realizado por Mistura, Schenkel, Rosa, e Girardon-Perlini (2014) constatou-se que, além de delegar as tarefas, os cuidadores tentavam antecipá-las o quanto fosse possível, buscando facilitar o cotidiano dos familiares que permanecem em casa. Tal atitude, entretanto, pode acabar gerando sobrecarga, uma vez que o cuidador assume essas responsabilidades concomitantemente com o cuidado da criança ou adolescente doente.

Estas mudanças na rotina familiar podem ser geradoras de estresse (Dupas, Silva, Nunes, \& Ferreira, 2012), especialmente quando relacionadas a aspectos como o aumento de gastos financeiros aliados à diminuição da renda, e à reorganização familiar no que se refere a inversão e divisões de papéis (Luz, Vargas, Barlem, Schimitt, Ramos, \& Meirelles, 2016).

Os dados sobre as mudanças nas famílias, acarretadas pelo adoecimento, permitem tecer algumas considerações. A abordagem sistêmica possibilita a compreensão da família como um sistema relacional, cujos membros se influenciam reciprocamente e sofrem influências recursivas do contexto social, econômico, histórico e cultural (Souza, 2009). Seguindo essa lógica, pode-se compreender que o adoecimento de um membro familiar tem repercussões no sistema e impõe, além das tarefas desenvolvimentais normativas referentes ao ciclo de vida da família (Carter \& McGoldrick, 1995; Cerveny \& Berthoud, 2009), desafios característicos ao processo de adaptação à doença. Neste estudo, o fato de uma criança ou adolescente ser acometido por um câncer impactou vários membros da família e contribuiu para o fortalecimento de relações familiares e criação de uma rede de apoio. Contudo, as influências socioculturais, que ainda contribuem para a existência do estigma relacionado ao câncer, somadas, provavelmente, a fragilidades nos vínculos familiares, acarretaram o afastamento dos membros, fomentando a vulnerabilidade dos familiares cuidadores. Deve-se considerar também que as mães cuidadoras, mesmo alegando uma maior união familiar, ainda se sentem sobrecarregadas por assumirem o papel de principal de cuidadoras de seus filhos, pois têm que cuidar do filho doente e também dos demais membros da família. Isto posto, reforça-se a necessidade do suporte dos profissionais de saúde, respaldado pelo conhecimento sobre os processos e dinâmicas familiares e sobre os desafios impostos às famílias, tendo em vista suas condições econômicas e sociais.

O pensamento sistêmico pode contribuir para uma assistência em saúde mais qualificada e condizente com as demandas dos cuidadores e suas famílias. Para isso, deve-se reconhecer a interdependência que caracteriza as relações entre e intrassistemas e a importância de contextualizar os fenômenos (pressuposto da complexidade); a imprevisibilidade e processos de auto-organização inerentes aos sistemas familiares (pressuposto da instabilidade), além do abandono da objetividade, no sentido de negar a existência de uma realidade independente do observador (pressuposto da intersubjetividade) (Vasconcellos, 2009). Esta proposta 
vai ao encontro dos princípios e diretrizes do SUS que buscam resgatar o olhar integral para análise das demandas trazidas pelos usuários, (incluindo a família), o trabalho colaborativo entre diferentes serviços (intersetorialidade), o protagonismo do usuário e a corresponsabilidade no cuidado em saúde. O psicólogo, nesse contexto, valoriza o singular contextualmente situado, busca apreender os significados atribuídos pelos sujeitos às suas experiências, pretere a busca pelas "verdades" dos fatos e a visão de expert, reconhecendo a sua participação no sistema como coconstrutor de soluções (Boing \& Crepaldi, 2014).

Defende-se que o estresse e o sofrimento psicológico das famílias pode ser minimizado mediante determinadas ações, em diferentes níveis de atenção, respaldadas por abordagens que considerem diferentes dimensões dos processos de saúde e doença, como as abordagens sistêmicas, ecológicas ou psicossociais. Nesse sentido, recomenda-se que os profissionais de saúde atuem em equipes interdisciplinares, tendo em vista diferentes contextos e dinâmicas familiares; promovam uma prática interprofissional e intersetorial que contemple as diferentes necessidades dos usuários; adotem uma postura acolhedora que permita a construção de vínculos entre equipe de saúde e usuários e atuem no sentido de construir rede de apoio com objetivo de disponibilizar diferentes tipos de apoio para as famílias (Moré, 2005).

Destaca-se o papel da Atenção Básica no acompanhamento do processo de enfrentamento do câncer, uma vez que tem como atributo essencial o vínculo longitudinal com os usuários (Santos, Romano, \& Engstrom, 2018) e o papel de contribuir para o diagnóstico precoce, oferecendo apoio para a população no que se refere à terapêutica de tumores e aos cuidados paliativos, por exemplo (Ministério da Saúde, 2005).

A escolha por outros serviços de saúde, os erros de diagnóstico, a sensação de não estar sendo escutado, a angústia e o sentimento de impotência decorrente do itinerário inicial para se obter o diagnóstico, principalmente no âmbito dos cuidados primários, alerta para a necessidade de fortalecimento da vinculação entre profissionais e familiares cuidadores. $\mathrm{O}$ vínculo, enquanto ferramenta essencial desse nível de atenção, possibilita a construção da confiança, da relação afetiva, bem como de um maior conhecimento sobre os usuários e suas histórias de vida. Ele é condição, portanto, para um diagnóstico correto e corresponsabilização dos sujeitos na produção de cuidado (Seixas et. al, 2019). Nos outros níveis de atenção, os profissionais da equipe de saúde também podem atuar prestando esclarecimentos sobre a proposta terapêutica, ofertando apoio emocional, proporcionando espaços nos quais esses familiares possam expressar seus sentimentos e angústias, para que o impacto emocional da experiência seja minimizado (Grant \& Traesel, 2010). As relações de apoio contribuem para a resiliência familiar, no sentido de transformação pessoal e relacional, envolvendo reavaliação da vida e maior investimento nas relações (Walsh, 2016).

Haja vista as diversas demandas e tarefas com que essas famílias têm que lidar, a adaptação familiar ao adoecimento oncológico está condicionada não apenas a recursos individuais, mas também a recursos relacionais, institucionais e sociais. A mobilização desses recursos, segundo Boing e Crepaldi (2014), deve ser tarefa compartilhada entre profissionais de saúde e de outros setores e implica uma mudança paradigmática, fomentada por reflexões a respeito das origens epistemológicas de teorias e práticas profissionais. Nesse contexto, faz-se ainda necessário ressaltar o grande desafio da gestão na perspectiva da construção de um projeto assistencial coletivo, que atenda às necessidades dessas famílias, voltado para a integralidade e para um agir cotidiano como força de mudança. 


\section{CONSIDERAÇÕES FINAIS}

Este estudo permitiu que se resgatasse a trajetória de famílias que vivenciam o câncer infantojuvenil, desde o aparecimento dos primeiros sinais e sintomas até a confirmação do diagnóstico oncológico, revelando o caminho longo e árduo que é percorrido nos serviços de saúde.

Os resultados permitem problematizar alguns aspectos da assistência em saúde direcionada aos pacientes oncológicos e suas famílias. Grande parte das queixas dos familiares direcionava-se à atenção primária à saúde, uma vez que o tempo para se chegar ao diagnóstico era percebido como longo e angustiante, gerando sentimento de impotência. Dessa forma, as vivências relatadas revelam a necessidade da adoção de um olhar complexo no campo da saúde, orientado pelo princípio da integralidade. Também aponta a imprescindibilidade de fortalecimento dos vínculos entre profissionais e usuários, no sentido de promover o protagonismo da família na produção do cuidado.

É preciso reconhecer que, pelo fato de o câncer ainda estar associado à representação simbólica de morte, incurabilidade e dor, o impacto do diagnóstico pode ser maior e a experiência de cuidar de uma criança ou adolescente com câncer, mais difícil. Acredita-se que uma comunicação adequada, com uma linguagem acessível ao contexto das famílias, na qual as informações acerca da patologia e da terapêutica a ser adotada sejam devidamente repassadas pode diminuir esse estigma. Diante disso, salienta-se a necessidade de que os profissionais possam repensar suas práticas de cuidado para que possam estar preparados para identificar adequadamente e, em tempo hábil, os sinais e sintomas do câncer, além de lidar com as repercussões clínicas, psicológicas e sociais advindas do adoecimento.

Recomenda-se que a rede de atenção oncológica fomente as articulações em torno do cuidado em saúde, de modo a compartilhar as responsabilidades e os compromissos entre seus diferentes níveis de assistência, tornando-se mais resolutiva e de qualidade. Ademais, é importante que se priorize o estabelecimento de uma relação de confiança na tríade usuário, cuidador e equipe de saúde, fomentando um trabalho comunicativo e humanizado, no qual os sujeitos envolvidos possam ser assistidos integralmente.

\section{REFERÊNCIAS}

Aguiar, J. M., D'Oliveira, A. F. P. L., \& Schraiber, L. B. (2013). Violência institucional, autoridade médica e poder nas maternidades sob a ótica dos profissionais de saúde. Cadernos de Saúde Pública, Rio de Janeiro, 29(11), 2287-2296. 
Alcântara, T. V., Shioga, J. E. M., Lima, M. J. V., Lage, A. M. V., \& Maia, A. H. N. (2013). Intervenções psicológicas na sala de espera: estratégias no contexto da oncologia pediátrica. Revista SBPH, Rio de Janeiro, 16(2), 103-119.

Almico, T. \& Faro, A. (2014). Enfrentamento de cuidadores de crianças com câncer em processo de quimioterapia. Sociedade Portuguesa de Psicologia da Saúde. Psicologia, Saúde e Doenças, Lisboa, 15(3), 723-737.

Alves, R. F. \& Eulálio, M. A. (2011). Abrangência e níveis de aplicação da Psicologia da Saúde. In R. F. Alves (Org.), Psicologia da Saúde: Teoria, intervenção e pesquisa (pp. 65-88). Campina Grande: EDUEPB

Amador, D. D., Reichert, A. P. S., Lima, R. A. G., \& Collet, N. (2013). Concepções de cuidado e sentimentos do cuidador de crianças com câncer. Acta Paulista de Enfermagem, São Paulo, 26(6), 542-546.

Bardin, L. (2009). Análise de Conteúdo. Lisboa: Edições 70.

Beltrão, M. R. L. R., Vasconcelos, M. G. L., Pontes, C. M., \& Albuquerque, M. C. (2007). Câncer infantil: percepções maternas e estratégias de enfrentamento frente ao diagnóstico. Jornal de Pediatria, Porto Alegre, 83(6), 562-566.

Bidin, C., Souza, M. R., \& Machineski, G. G. (2013). A importância dos cuidados de enfermagem para crianças com câncer e seus familiares: uma revisão bibliográfica. Revista Thêma et Scientia, Paraná, 3(2), 106-113.

Boing, E. \& Crepaldi, M.A. (2014). Reflexões epistemológicas sobre o SUS e a atuação do psicólogo. Psicologia: Ciência e Profissão, Brasília, 34(3), 745-760.

Borges, A. A. (2013). Processo comunicacional familiar no contexto do câncer infantil. Dissertação de Mestrado, Programa de Pós-graduação em Ciências da Saúde. Universidade Federal de São Carlos, São Paulo. Recuperado de https://repositorio. ufscar.br/bitstream/handle/ufscar/3256/4968.pdf? sequence $=1$ \&isAllowed $=\mathrm{y}$

Borges, A. A., Lima, R. A. G., \& Dupas, G. (2016). Segredos e verdades no processo comunicacional da família com a criança com câncer. Escola Anna Nery Revista de Enfermagem, Rio de Janeiro, 20(4), 1-9.

Carter, B. \& McGoldrick, M. (1995). As mudanças no ciclo de vida familiar: uma estrutura para a terapia familiar (2a ed.). Porto Alegre: Artes Médicas.

Carvalho, A. S., Depianti, J. R. B., Silva, L. F., Aguiar, R. C. B., \& Monteiro, A. C. M. (2014). Reactions of family members of children diagnosed with cancer: a descriptive study. Online brazilian journal of nursing, 13(3), 282-291.

Cavicchioli, A. C., Menossî, M. J., \& Lima, R. A. G. (2007). Câncer infantil: o itinerário diagnóstico. Revista Latino-Americana de Enfermagem, Ribeirão Preto, 15(5), 1025-1032.

Cerveny, C. M. O. \& Berthoud, C. M. E. (2009). Ciclo vital da família brasileira. In L. C. Osorio \& M. E. P. Valle (Orgs.), Manual de terapia familiar (pp. 25-75). Porto Alegre: Artmed.

Del Bianco Faria, A. M. \& Cardoso, C. L. (2010). Aspectos psicossociais de acompanhantes cuidadores de crianças com câncer: stress e enfrentamento. Estudos de Psicologia, Campinas, 27(1), 13-20.

Denzin, N. K. \& Lincoln, Y. S. (2006). A disciplina e a prática da pesquisa qualitativa. In N. K. Denzin (Org.), O planejamento da pesquisa qualitativa: teorias e abordagens (pp. 15-41). Porto Alegre: Artmed.

Dupas, G., Silva, A. C., Nunes, M. D. R., \& Ferreira, N. M. L. A. (2012). Câncer na infância: Conhecendo a experiência do pai. Revista Mineira de Enfermagem, 16(3), 348-354.

Fagundes, C. S. 0., Silva, M. F., Siva, R. F., \& Barbosa, H. A. (2015). "Senti culpa, muita tristeza e vontade de chorar” - percepções sobre o câncer para mães e cuidadores 
de crianças em tratamento oncológico. Revista Bionorte, Minas Gerais, 4(2), 48-60.

Fermo, V. C., Lourençatto, G. N., Medeiros, T.S., Anders, J. C. \& Souza, A. I. J. (2014). O diagnóstico precoce do câncer infantojuvenil: o caminho percorrido pelas famílias. Escola Anna Nery Revista de Enfermagem, Rio de Janeiro, 18(1), 54-59.

Ferreira, A. C. S., Duarte, B. C., Machado, L. R., Brandão, M. Pr A.y Baiense, S. N., Mello, D. R. B. \& Vitarelli, A. M. (2018). Comunicação entre médico e paciente frente ao diagnóstico. Revista Interdisciplinar do Pensamento Científico, Rio de Janeiro, 4(1), 108-115.

Ferreira, N. M. L., Dupas, G., Costa. D. B., \& Sanchez, K. O. Ls (2010). Câncer e família: compreendendo os significados simbólicos. Revista Ciência, Cuidado e Saúde, 9(2), 269-277.

Fornari, L. F., Madureira, A. B., Labronici, L. M.s \& Mantovani, M. F. (2014). Violência institucional em unidades básicas de saúde sob o olhar de usuárias. Cogitare enfermagem, Paraná, 19(4), 673-678.

Friestino, J. K. 0. (2015). Panorama do câncer em crianças e adolescentes sob a perspectiva da saúde coletiva. Dissertação de Mestrado, Programa de Pósgraduação em Saúde Coletiva, Universidade Estadual de Campinas, SP.

Frizzo, N. S., Quintana, A. M.s Salvagni, A., Barbieri, A.s \& Gebert, L. (2015). Significações dadas pelos progenitores acerca do diagnóstico de câncer dos filhos. Psicologia, Ciência e Profissão, Brasília, 35(3), 959-972.

Grant, C. H. \& Traesel, E. S. (2010). Vivências de cuidadores de crianças e adolescentes com câncer: uma reflexão sobre o apoio psicológico. Revista DisciplinarumScientia, Santa Maria, 11(1), 89-108.

Instituto Nacional De Câncer - INCA. (2020a). Tipos de Câncer - Câncer Infantojuvenil. Recuperado de https://www.inca.gov.br/tipos-de-cancer/cancer-infantojuvenil

Instituto Nacional De Câncer - INCA. (2020b). Sobre o Inca - Institucional. Recuperado de https://www.inca.gov.br/institucional

Kohlsdorf, M. \& Costa, A. L. (2012). Impacto psicossocial do câncer pediátrico para pais: revisão da literatura. Paidéia, Ribeirão Preto, 22(51), 119-129.

Lima, B. C., Silva, L. F., Góes, F. G. B., Rỉbeiro, M. T. S., \& Alves, L. L. (2018). O itinerário terapêutico de famílias de crianças com câncer: dificuldades encontradas neste percurso. Revista Gaúcha de Enfermagem, Porto Alegre, 39, 1-9.

Luz, K. R., Vargas, M. A. 0., Barlem, E. L. D., Schmitt, P. H., Ramos, F. R. S., \& Meirelles, B. H. S. (2016). Estratégias de enfrentamento por enfermeiros da oncologia na alta complexidade. Revista Brasileira de Enfermagem, Brasília, 69(1), 67-71.

Martins, C. B. S., Silva, N. \& Pires, M. L. N. (2011). Estratégias de coping e o impacto sofrido pela família quando um dos seus está em tratamento contra o câncer. Mudanças, Psicologia da Saúde, 19(1-2), 11-8.

Mazza, V. A., Lima, V. F., Carvalho, A. K. S., Weissheimer, G., \& Soares, L. G. (2017). Informações online como suporte às famílias de crianças e adolescentes com doenças crônicas. Revista Gaúcha de Enfermagem, Porto Alegre, 38(1), 1-9.

Melo, M. C. B., Barros, E. N., Campello, M. C. V. A., Ferreira, L. Q. L., Rocha, L. L. C., Silva, C. I. M. G. \& Santos, N. T. F. (2012). O funcionamento familiar do paciente com câncer. Psicologia em Revista, Minas Gerais, 18(1), 73-89.

Merhy, E. E. (2007). Saúde: a cartografia do trabalho vivo em ato (3a ed.). São Paulo: Hucitec.

Minayo, M. C. (1993). O desafio do conhecimento: pesquisa qualitativa em saúde. Rio de Janeiro: Hucitec. 
Ministério da Saúde. (2005). Política Nacional de Atenção Oncológica. Brasília, DF: Autor. Recuperado de https://bvsms.saude.gov.br/bvs/publicacoes/politica_ nacional_atencao_oncologica.pdf

Mistura, C., Schenkel, F. W., Rosa, B. V. C. \& Girardon-Perlini, N. M. O. (2014). A experiência em acompanhar um membro da família internado por câncer. Fundam. care. online, 6(1), 47-61.

Moré, C. L. O. 0. (2005). As redes pessoais significativas como instrumento de intervenção psicológica no contexto comunitário. Paidéia, Ribeirão Preto, 15(31), 287-297.

Nehmy, R. M. Q., Brito, A. C., Mota, J. A. C., \& Oliveira, B. M. (2011). A perspectiva dos pais sobre a obtenção do diagnóstico de leucemia linfoide aguda em crianças e adolescentes: uma experiência no Brasil. Revista Brasileira de Saúde Materno Infantil, Recife, 11(3), 293-299.

Nunes, L. C. B., Pedrosa, A. D. 0. M., Barbosa, A. A., Monteiro, H., \& Ferraz, L. M. (2017). A Criança Entra em Cuidados Paliativos: O Sentimento do Cuidador Frente à Notícia. Revista Portal: Saúde e Sociedade, Alagoas, 2(1), 319-331.

Ongaro, J. L. E. P. D. \& Zucolotto, M. P. R. (2016). Câncer e o paciente em tratamento oncológico: percepções do familiar cuidador. DisciplinarumScientia, Santa Maria, 17(1), 83-101.

Piccardi, T: (2012). O não reconhecimento do outro em interlocuções entre médicos e pacientes: simulacro e ethos na prática médica. Revista theESPecialist, São Paulo, 33(2), 192-202.

Quirino, D. D. (2011). Cotidiano da família no enfrentamento do câncer infantil. Dissertação de Mestrado, Programa de Pós-graduação em Enfermagem. Universidade Federal da Paraíba, João Pessoa, PB.

Reis, J., Dias, S. P.s \& Mazzaia, M. C. (2009). A assistência da criança na atenção básica e sua relação com o diagnóstico tardio do câncer infantil. Revista Brasileira de Ciências da Saúde, São Caetano do Sul, 20, 7(20), 52-62.

Rezende, A. M. (2015). Câncer infanto-juvenil: aspectos psicossociais. Tese de Doutorado, Programa de Pós-graduação em Ciências da Saúde, Fundação Oswaldo Cruz, Belo Horizonte, MG. Recuperado de http://www.cpqrr.fiocruz. br/texto-completo/T_101.pdf

Rezende, A. M., Schall, V. T., \& Modena, C. M. (2009). O "adolescer" e adoecer: vivência de uma adolescente com câncer. Aletheia, Canoas, 30, 88-100.

Rolland, J. (2016). Enfrentando os desafios familiares em doenças graves e incapacitantes. In F. Walsh (Ed.), Processos normativos da família (pp. 452-482). Porto Alegre: Artmed.

Sá, A. C. S. Silva, A. C. S. S., \& Góes, F. G. B. (2019). Diagnóstico do Câncer Infantojuvenil: O Caminho Percorrido Pelas Famílias. Cuidado é Fundamental, Rio de Janeiro, 11(5), 1180-1187.

Salci, M. A. \& Marcon, S. S. (2008). De cuidadora a cuidada: quando a mulher vivencia o câncer. Texto Contexto Enfermagem, 17(3), 544-551.

Sales, C. A.r Santos, G. M., Santos, J. Ar, \& Marcon, S. S. (2012). O impacto do diagnóstico do câncer infantil no ambiente familiar e o cuidado recebido. Revista Eletrônica de Enfermagem, Goiânia, 14(4), 841-849.

Salvagni, A. (2014). Implicações do câncer infantil na dinâmica familiar. Dissertação de Mestrado, Programa de Pós-graduação em Psicologia, Universidade Federal de Santa Maria, Santa Maria, Rio Grande do Sul, RS. Recuperado de http://w3.ufsm. br/ppgp/images/dissertacoes/2013-2014/adelise-salvagni.pdf

Santos, R. 0. M., Romano, V. F., \& Engstrom, E. M. (2018). Vínculo longitudinal na saúde da família: construção fundamentada no modelo de atenção, práticas 
interpessoais e organização dos serviços. Physis: Revista de Saúde Coletiva, Rio de Janeiro, 28(2), 1-18.

Seixas, C. T., Baduy, R. S., Cruz, K. Tu, Bortoletto, M. S. S., Slomp, H., \& Merhy, E. E. (2019). O vínculo como potência para a produção do cuidado em saúde: o que os usuários-guia nos ensinam. Interface comunicação, saúde, educação, Botucatu, $23,1-14$.

Souza, M. T. S. (2009). Terapia familiar e resiliência. In L. C. Osorio \& E. Valle (Orgs.), Manual de terapia familiar (pp. 193-207). Porto Alegre: Artmed.

Theobald, M. R., Santos, M. L. M.y Andrade, S. M. O., \& De-Carli, A. D. (2016). Percepções do paciente oncológico sobre o cuidado. Physis Revista de Saúde Coletiva, Rio de Janeiro, 26(4), 1249-1269.

Vasconcellos, M. J. E. (2009). Pensamento sistêmico: o novo paradigma da ciência. Campinas, SP: Papirus.

Vidotto, P. C. P., Ferraril, R. A. P., Tacla, M. T: G. M., \& Facio, B. C. (2017). Experiência materna no itinerário diagnóstico do câncer infantil. Revista de enfermagem da UFPE online, Recife, 11(4), 1565-1573.

Walsh, F. (2016). Processos normativos da família: diversidade e complexidade. Porto Alegre: Artmed.

\section{BEATRIZ LIMA FIGUEIRÊDO}

Psicóloga, Especialista em Saúde Mental e Mestre em Psicologia da Saúde.

Endereço institucional: Universidade Estadual da Paraíba - R. Baraúnas, 351 Universitário, Campina Grande - PB, 58429-500.

https://orcid.org/0000-0003-2880-3211

E-mail: psi.beatrizlima@gmail.com

\section{SIBELLE MARIA MARTINS DE BARROS}

Psicóloga. Professora Doutora do Departamento de Psicologia e do Programa de Pós-graduação em Psicologia da Saúde da UEPB. Membro do Grupo de Trabalho «Família e Comunidade», vinculado à Associação Nacional de Pesquisa e PósGraduação em Psicologia (ANPEPP).

https://orcid.org/0000-0003-0933-5475

E-mail: sibelle@servidor.uepb.edu.br

\section{MARIA ANGÉLICA CARVALHO ANDRADE}

Departamento de Medicina Social, Programa de Pós-Graduação em Saúde Coletiva (PPGSC), Universidade Federal do Espírito Santo (UFES), Vitória, Espírito Santo. https://orcid.org/0000-0002-3690-6416

E-mail: geliandrade@gmail.com 